\title{
AVALIAÇÃO ÉTICA E POLÍTICA EM FUNÇÃO DA EDUCAÇÃO COMO DIREITO PÚBLICO OU COMO MERCADORIA?
}

\author{
José Dias SOBRinho*
}

\begin{abstract}
RESUMO: Neste texto, trato da vinculação da avaliação às reformas da educação superior e suas relações com o Estado. Sustento que a avaliação tem papel não só técnico, mas sobretudo ético e político de grande importância nas transformações e reformas da educação superior e da própria sociedade. De modo particular, distingo dois paradigmas. Um que concebe a educação superior segundo a lógica do mercado, outro que concebe a educação superior como um bem público. A cada um desses paradigmas corresponde uma epistemologia e um modelo de avaliação, com seus fundamentos científicos, suas ideologias e seus efeitos na vida social, política e econômica. Um concebe a avaliação sobretudo como controle. $\mathrm{O}$ outro concebe a avaliação sobretudo como produção de sentidos. Isto faz da avaliação um campo cheio de contradiçôes e de múltiplas referências. Portanto, ela deveria ser tratada por teorias da complexidade e exercitada mediante uso de diversos instrumentos e a combinação de diferentes abordagens. A compreensão de todos esses aspectos é importante para não perder de vista que devem ser formativos os objetivos de uma avaliação educativa. Então, a avaliação deve ser, essencialmente, um processo social que põe em questão os sentidos da formação.
\end{abstract}

Palavras-chave: Educação superior. Avaliação. Epistemologias objetivistas. Epistemologias subjetivistas. Controle. Produção de sentidos.

\section{Ethical and POLITICAL ASSESSMENT. REgaRding EDUCATION AS A PUBLIC RIGHT OR AS A COMMODITY?}

ABSTRACT: This paper deals with the links between assessment and the higher education reforms and their relation to the State. It

\footnotetext{
* Professor titular, aposentado, colaborador voluntário da Universidade Estadual de Campinas (UNICAMP), professor do Curso de Pós-Graduação em Educação da Universidade de Sorocaba (UNISO).E-mail: jdias@unicamp.br.
} 
Avaliação ética e política em função da educação como direito público ou...

advocates that assessment plays a crucial role not only technically, but also, and mainly, ethically and politically, in the changes and reforms in higher education and in society. It highlights two paradigms which conceive higher education as a product ruled by market logics and as a public right, respectively. Each has its epistemology and assessment model, with their scientific groundings, ideologies and effects on the social, political and economical life. The first one conceives assessment mainly as control, the other, as production of meaning. This turns assessment into an area full of contradictions and multiple references. It should thus be dealt with through complexity theories and applied using several instruments and combining different approaches. Understanding all these aspects is important to keep in mind that an educative assessment must have formative goals. Assessment must then be essentially a social process that questions the meanings of the formative endeavor.

Key words: Higher education. Assessment. Quantitative epistemology. Qualitative epistemology. Control. Production of meanings.

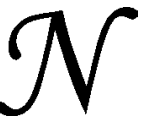

ão há como compreender as transformações da educação superior, nos últimos anos, sem levar em conta as práticas de avaliação. Há uma forte disputa entre duas concepções de educação superior que também carregam contradições muito importantes nas concepçóes e nas práticas de avaliação. Isso pelo reconhecimento de que a avaliação exerce um papel de motor das transformações nos sistemas e nas instituições de educação superior e, por conseqüência, na sociedade. Dessa forma, a educação superior tem sido considerada uma instituição que produz conhecimentos e forma cidadãos para as práticas da vida social e econômica, em benefício da construção de nações livres e desenvolvidas. Em posição distinta, cresce e se fortalece hoje a defesa da educação superior como função da economia e dos interesses individuais e privados. Essas diferenças ideológicas relativas ao papel social da educação superior interferem fortemente na compreensão das funções da avaliação. "Aqueles que vêm a escola como uma instituição constitutiva da República querem que a escola forme o cidadão; (...). Os que vêm a escola como uma empre$s a$, num vasto mercado de formação, encontram uma real necessidade na avaliação do sistema, por múltiplas razôes. É preciso conhecer, portanto avaliar, a oferta e a demanda para encontrar a melhor ade- 
quação. É preciso permitir ao consumidor escolher, então fornecerlhe informações. É preciso pilotar o sistema educativo como uma empresa em busca da melhor eficácia” (Vogler, 1996, p. 346-347).

Por aí já podemos ver que avaliação da educação superior é um dos temas mais complicados e complexos, tanto para quem se dedica à teoria quanto para quem se envolve em sua prática. Essa complexidade advém do fato de que não há consensos sobre avaliação em geral e tampouco existem muitos acordos sobre o que seja hoje a educação superior e, sobretudo, quais são as suas funções mais importantes na sociedade. Questôes epistemológicas, éticas, ideológicas, políticas, culturais, técnicas e de outras naturezas imprimem complexidade a esse fenômeno. Dissenso e contradições são inerentes aos fenômenos sociais, e não seria diferente na educação. Compreendendo que a avaliação carrega consigo a problemática sempre plural dos valores, e, então, da ética e da cultura, e que a educação superior tem igualmente um sentido fortemente social, portanto, também, ético, cultural e político, podemos entender que essa relação é cruzada de concepções de mundo e interesses bastante diferenciados. Nenhuma avaliação é neutra, tampouco nenhuma concepção de educação superior se isenta de visóes de mundo e idéias de sociedade ideal.

Avaliação e educação superior devem ser entendidas como fenômenos sociais e históricos. Não lhes servem as "idéias" essencialistas que as capturam e imobilizam em conceitos que não conseguem acompanhar as transformações históricas e os papéis que esses fenômenos sociais cumprem em circunstâncias distintas da vida das sociedades. Por exemplo, por mais rica que tenha sido a "idéia" da universidade formulada por Humboldt, essa noção ideal não mais corresponde com exatidão às transformaçōes da educação superior, atualmente mais próxima da forma de "multiversidade". Também é simplista e redutora a idéia de avaliação como um instrumento neutro e capaz de determinar de forma absolutamente objetiva o que é bom ou o que não o é. Como fenômenos sociais, educação superior e avaliação sofrem mudanças e cumprem papéis dinâmicos, respondendo às demandas que lhes são feitas nas mais diversas circunstâncias históricas.

Seus caminhos interconectam-se. Há uma interatuação nas transformaçōes que ocorrem nas avaliaçōes e na educação superior, uma não se transformando sem a transformação da outra. Nem do ponto de vista técnico, nem quanto a seus propósitos, a avaliação de hoje pode ser 
Avaliação ética e política em função da educação como direito público ou...

considerada a mesma que aquela praticada em outros tempos; por exemplo, quando servia à seleção de indivíduos para o serviço público ateniense, ou para a distribuição de empregados na indústria nascente na primeira Revolução Industrial. Ela se tornou crescentemente mais complexa, mais bem definida do ponto de vista instrumental e cada vez mais plurirreferencial. Seu alcance alargou-se e seus efeitos ampliaram-se. Tão importante quanto isso é que ampliou enormemente o âmbito dos interessados em seus resultados. Daí por que também se tenha preocupado tanto com as normas de procedimentos públicos e aceitos pelos grupos de interessados.

Ao voltar-se para programas, instituições e projetos com nítido sentido social e de amplo interesse, ao envolver recursos públicos e ao ser executada por muitas pessoas, especializadas ou não, a avaliação tornou-se declaradamente um fenômeno político, por mais que ideologicamente se queira apresentá-la como exclusivamente técnica. A avaliação em nossos dias é cada vez mais assunto que interessa a toda a sociedade, especialmente àquelas comunidades mais concernidas por seus resultados e efeitos. Mas, atualmente, são os Estados os principais interessados e aplicadores da avaliação, especialmente na perspectiva das reformas, do controle e da regulação. Tão importante é o papel da avaliação do ponto de vista político e tão eficiente é ela para modelar sistemas e garantir determinadas práticas e ideologias que nenhum Estado moderno deixa de praticá-la de modo amplo, consistente e organizado. Isto é, como política pública.

A avaliação da educação superior ultrapassa amplamente os âmbitos mais restritos do objeto a que se dirige. Seus efeitos atingem não só o sistema de educação superior como também têm impactos sobre toda a sociedade. A avaliação instrumentaliza as reformas educacionais, produzindo mudanças nos currículos, na gestão, nas estruturas de poder, nas configuraçôes gerais do sistema educativo, nas concepções e prioridades da pesquisa, nas noções de responsabilidade social, enfim, tem a ver com as transformações desejadas não somente para a educação superior propriamente dita, mas para a sociedade que se quer consolidar ou construir.

Além de política, há uma forte dimensão ética na avaliação. Ernest House talvez tenha sido um dos primeiros autores da área a explicitar com muita clareza esses sentidos: "Há muitas pessoas interessadas, porque as decisões sobre um programa baseadas na avaliação afetarão a to- 
dos. A avaliação faz parte, de maneira fundamental e inextricável, de uma situação pública: uma decisão coletiva" (House, 1994, p. 19). Quanto à questão ética, referindo-se ao avaliador, diz: "Sua avaliação não só deve ser veraz e crível, também deve ser justa” (House, 1994, p. 19 e 22).

Desde muito cedo, testes, provas, exames marcam os ritmos e os ritos de passagem do calendário escolar, como se fizessem parte da essência mesma das aprendizagens e das formações, como se a qualidade da formação de um aluno coincidisse com os resultados que alcança nesses instrumentos de verificação. $\mathrm{Na}$ realidade, a avaliação nem sempre é aplicada com função pedagógica, formativa e, portanto, de emancipação pessoal e social. Muito comumente, ela tem exercido funções de controle, seleção social, restrições à autonomia. O fenômeno da avaliação tem sentidos muito mais amplos e complexos que aqueles que as noçóes escolares mais singelas e o senso comum transmitem de geração a geração. Não cabe aqui deslindar todos os sentidos, nem sequer sugerir as dimensóes que constituem este fenômeno, tampouco suas evoluçôes históricas e seus impactos nas instituições sociais e nas suas relações com o Estado e a sociedade civil. Como já mencionei em outra parte, para uma visão mais ampliada seria

importante compreender - a lista não é exaustiva - as condições de sua emergência nos distintos períodos históricos, interpretar os diversos sentidos que ela vai adquirindo nos distintos contextos, suas funções variáveis, os modos e condições também mutáveis de sua produção, as tensões que produz nos âmbitos sociais e políticos, as configuraçôes temporais das instituiçõos escolares e universitárias, as tendências e perspectivas do ensino e da pesquisa, as políticas educacionais ligadas aos interesses dos governos e da economia, a difusão, o tratamento dado pela mídia, a recepção pelas comunidades educativas e por setores mais organizados da sociedade, as instâncias administrativas e legislativas, os sistemas de premiação e de financiamento, os grupos de especialistas vinculados às instituições de educação e às instâncias do poder, as agências, as audiências, o discurso da meta-avaliação, as revistas, os textos e autores da área consagrados. (Dias Sobrinho, 2002, p. 34)

Cabe fazer uma outra observação. Nem sempre são os resultados da avaliação que prevalecem nas tomadas de decisão dos governos. Muitas vezes, as políticas governamentais organizam as avaliações, não o inverso. Isso cria uma grande contradição. Se de um lado não há hipótese de pleno consenso sobre as questóes sociais em geral e em especial 
Avaliação ética e política em função da educação como direito público ou...

sobre os objetivos da sociedade, por outro lado os órgãos de administração pública exigem que os resultados das avaliações se apresentem de forma objetiva e inquestionável.

Desde a crise econômica e o aumento das demandas sociais dos anos de 1970, ou seja, com a diminuição dos recursos públicos para os setores sociais coincidindo com a crescente complexidade da sociedade, nos países industrializados, os Estados aumentaram consideravelmente as suas ações de controle e fiscalização. Este fenômeno se tornou conhecido como "Estado Avaliador", segundo expressão cunhada por Guy Neave, e caracteriza a forte presença do Estado no controle dos gastos e dos resultados das instituições e dos órgãos públicos. O "Estado Avaliador" intervém para assegurar mais eficiência e manter o controle daquilo que considera ser qualidade. Para a educação superior tornou-se obrigatório o aumento da eficiência de acordo com a fórmula: produzir mais, com menos gastos. A forte presença do "Estado Avaliador" faz com que as avaliações protagonizadas pelos governos sejam quase exclusivamente externas, somativas, focadas nos resultados e nas comparações dos produtos, para efeito de provocar a competitividade e orientar o mercado, e se realizam expost.

Tendo em vista a necessidade de aumentar a produtividade e a competitividade, houve um aparente ganho de autonomia. Entretanto, a autonomia concedida nesse âmbito de forte intervenção no campo social, que caracteriza o neoconservadorismo, consiste apenas em maior liberdade de organização e gestão, principalmente para maior adequação às necessidades diferenciadas do mercado e mais facilidade para a obtenção e utilização de recursos extra-orçamentários. Em contrapartida, a autonomia universitária é restringida pelas medidas de controle praticadas sob o nome de avaliação. Como as empresas, as instituiçõos educativas devem agora submeter-se aos critérios economicistas e gerenciais das empresas. Van Vught, referindo-se às reformas da educação superior da Holanda, diz:

A idéia de avaliar a eficiência das instituições de ensino superior parece ser a pedra angular da nova estratégia governamental. Do ponto de vista do governo, as decisōes referentes ao financiamento das instituições estarão baseadas em grande medida em juízos sobre a eficiência das instituições, que se obterão mediante um sistema de controle da qualidade. (Neave $\&$ Van Vught, 1994, p. 213) 
Todos os Estados que hoje buscam realizar importantes mudanças no setor público, na administração e nas formas de organização e produção da sociedade acabam elegendo a avaliação como o motor principal das reformas. Todos esses países criaram agências e uma rede bem articulada de especialistas para a promoção de avaliaçóes que ajudem a controlar e viabilizar os objetivos das reformas. Além disso, os principais organismos multilaterais impóem seus modelos avaliativos aos países beneficiários de financiamentos, exportam expertos e formam especialistas locais para a reprodução e implementação de instrumentos de controle de resultados conectados com as reformas gestadas nos grandes centros políticos e econômicos. Nesta perspectiva da orientação dominante imposta pelos países centrais e organismos multilaterais que lhes dão apoio, a avaliação cumpre a função primordial de tornar a educação superior mais efetivamente útil ao mundo dos negócios e do trabalho, mais voltada à satisfação das demandas do mercado, mais adequada à expansão das redes comerciais interdependentes.

Entretanto, nem toda educação superior tem como função prioritária servir ao mercado, embora este constitua hoje a face mais visível de um fenômeno de múltiplos prismas. Igualmente, embora nem toda avaliação esteja a serviço dos interesses privados e do mercado, também é preciso reconhecer que as relações de cooperação da avaliação com a economização da educação e da sociedade têm sido uma tendência cada vez mais forte. Há também importantes avaliações orientadas a apoiar a formação da consciência crítica, da cidadania, da identidade nacional, mediante o desenvolvimento do debate e da reflexão coletiva sobre as funções públicas da educação superior. Neste caso, estes processos avaliativos se vinculam àqueles que constroem os conhecimentos e promovem os valores como bens públicos a serviço da população em geral, não como propriedades privadas a serviço do interesse individual.

Claro que esta polarização - bem público X bem privado - não é nem absoluta, dadas as possibilidades de hibridismos, nem isenta de tensôes, como sempre ocorre nos âmbitos sociais e, por isso, ideológicos. A economia é uma dimensão imprescindível da vida humana, a ser adequadamente desenvolvida pela educação. O papel da educação como motor da economia deve também ser levado em conta. Entretanto, a economia não pode se desbordar na economização da vida humana, ou seja, não pode ser tomada como o centro do desenvolvimento civilizacional, não pode ser a referência central e primordial dos valores 
Avaliação ética e política em função da educação como direito público ou...

da vida pessoal e social. Da mesma forma, a avaliação não deve ser instrumento dessa funcionalização economicista.

Importante marcar que essas diferentes funções e concepções de avaliação são coerentes com determinadas concepções de educação superior e com certos interesses e valores de grupos sociais. Não são dois blocos homogêneos. Assim mesmo, há sensíveis predominâncias de idéias e práticas que priorizam a função ético-política, que consiste na democratização e no aprofundamento dos valores públicos, ou, por outro lado, a função técnico-burocrático-economicista, que prioriza as bases do mercado, a gestão eficaz, o progresso das empresas e o sucesso individual. O problema deste segundo bloco não está na eficiência e no "progresso" que ele produz, mas sim no fato de que não está a serviço dos interesses comuns de elevação espiritual e material de toda a sociedade.

Em outras palavras, sempre advertindo para as possibilidades de existirem configurações híbridas, podem-se distinguir analiticamente duas tendências dominantes na avaliação, conforme se lhe atribua mais a função ético-política de formação da cidadania, promoção de sujeitos autônomos, emancipação e solidariedade social, ou, preponderantemente, a função técnico-burocrático-economicista, pretensamente objetiva, de controle dos produtos e instrumentalização da educação em função da economia de mercado. No primeiro caso, ainda que não exclusivamente, situam-se aqueles que defendem os valores históricos da universidade referenciada à sociedade. No segundo, como tendência e também não de modo puro, em geral colocam-se governos, organismos multilaterais, instâncias reguladoras, setores universitários a serviço do mercado, ou simplesmente adeptos da idéia de que se pode tratar a realidade sem contaminação ideológica.

Dois conceitos importantes aqui se insinuam: autonomia e regulação. Estes termos são susceptíveis de múltiplas interpretações, não faltando quem lhes atribua uma oposição simples e sem contradições. Portanto, não se há de incorrer no equívoco, bastante comum, de opor o primeiro termo ao outro, porém muito menos contrapor avaliação e autonomia. Se assim fosse, a avaliação identificar-se-ia simplesmente com controle. Seria, então, um instrumento que poderia negar ou suspender a autonomia.

É importante jamais perder de vista a complexidade da avaliação. Nem poderia ser diferente, pois toda avaliação tem a ver com idéias, 
qualidades, escolhas, valores, interesses, grupos, instâncias, poder. Como tudo isso é diverso e dinâmico, a avaliação não poderia esgotar-se em instrumentos e sentidos simples, unívocos, monorreferenciais. Pode-se mesmo observar que, à medida que as sociedades se tornam mais complexas, quando surgem mais problemas, mais mudanças nos campos da economia, da política, da cultura, bem como quando há mais avanços nos sistemas de produção, distribuição e utilização dos conhecimentos, a avaliação também adquire novas formas e novos conteúdos, ajustados a essas dinâmicas históricas. Apesar da diversidade que vai apresentando em consonância com as transformações societais, dois grandes tipos básicos sobressaem-se, quando olhados pelos prismas da epistemologia, da ética e dos efeitos políticos que produzem. House chama-os de "enfoques" ou "modelos", acrescentando que eles compartilham as idéias da sociedade em que são praticados.

Embora sempre lembrando a complexidade epistemológica e as implicações éticas e políticas da avaliação, o que apresento a seguir são apenas indicações básicas da epistemologia objetivista e da epistemologia subjetivista, que sustentam dois dos modelos avaliativos mais recorrentes e concorrentes.

\section{Epistemologia objetivista em avaliação}

No liberalismo e, atualmente, no neoliberalismo econômico e no neoconservadorismo político, prevalecem a liberdade de escolha, o individualismo, o empirismo e um tipo de sociedade de caráter dominantemente mercantil, competitivo e individualista. Ao passo que o neoliberalismo se refere à economia, preconizando liberdade nos processos para facilitar o livre comércio, o neoconservadorismo diz respeito a um maior controle por parte do Estado sobre o campo social e cultural. House já havia observado, em 1980, que as características da sociedade liberal (e penso que isso vale para o neoliberalismo e o neoconservadorismo atuais) são idéias-chave que constituem basicamente os enfoques avaliativos. Referindo-se ao liberalismo, enfatiza: "A idéia mais fundamental é a liberdade de escolha, porque, se ela falta, que utilidade tem a avaliação?" (House, 1994, p. 46). Vale observar que a liberdade de escolha é essencial para a liberdade comercial. No caso da educação, essa liberdade é fundamental para sustentar a privatização, tanto na ponta da oferta quanto da recepção dos serviços e produtos educacionais. É claro que na ques- 
Avaliação ética e política em função da educação como direito público ou...

tão da educação privada é imprescindível que haja as adequadas condições econômicas. Porém, se também não houvesse possibilidades de escolha, como se sustentariam as ofertas privadas? Os instrumentos avaliativos, que buscam orientar objetivamente as opções dos "clientes", só fazem sentido onde vige o princípio da livre escolha.

A avaliação fundada na epistemologia objetivista diz-se eminentemente técnica. Seu objetivo principal é prestar informações objetivas, científicas, claras, incontestáveis, úteis para orientar o mercado e os governos. Justifica-se pela idéia de que os clientes ou usuários da educação têm individualmente o direito de saber quais são as boas escolas, os bons professores, quem oferece os melhores serviços, segundo parâmetros prévia e objetivamente estabelecidos e levando em conta a relação custo-benefício. Esses parâmetros, normas e critérios, supostamente objetivos, ideais e abstratos, quase sempre se utilizam de procedimentos de quantificação de produtos, dada a necessidade de comparações e rankings, e estão voltados ao controle da qualidade dos serviços e produtos educacionais, à semelhança do que ocorre no mundo dos negócios. O controle, nessa perspectiva, efetua-se conforme a crença de que a avaliação seria neutra e objetiva, dado seu suposto caráter técnico. Objetividade, certeza, neutralidade, verificabilidade seriam asseguradas pelos procedimentos científicos, pelo uso de instrumentos objetivos e técnicas quantitativas.

A epistemologia objetivista em educação e mais especificamente em avaliação tem na "gestão científica", na "pedagogia por objetivos", na "psicometria" e na "cienciometria" algumas de suas mais importantes manifestações, na linha da ideologia do individualismo, do sucesso individual, da eficiência e da racionalidade instrumental. Objetivos e qualidades poderiam e, então, deveriam ser medidos, quantificados, comparados. Os testes, as escalas, as estatísticas e os rankings são recursos privilegiados para verificar, controlar e produzir eficiência e qualidade, mas segundo noçóes de eficiência e qualidade que correspondam a essa racionalidade.

Ao longo do século XX, desenvolveu-se uma grande indústria de instrumentos de medida. A primeira grande contribuição (presente até hoje, transformada) veio da psicologia. Com efeito, a psicologia desenvolveu-se nas primeiras décadas do século passado basicamente como psicometria, com grande destaque a E. L. Thorndike, na elaboração de testes para fins de classificação. Mais tarde, a sociologia do conhecimento contribuiu para o desenvolvimento de um aspecto importante na ava- 
liação-mensuração da produção científica. A partir de 1943, Robert Merton e outros elaboraram as bases das medidas e quantificações da produção científica, que vieram a ser conhecidas por cienciometria; posteriormente, foram criados institutos dedicados à quantificação e indexação de citações científicas. Essa metodologia se universalizou e é largamente utilizada nos levantamentos dos produtos de pesquisa e no reconhecimento de mérito dos cientistas e pesquisadores. Nos últimos anos, de modo especial desde os anos de 1970 e após a generalização das crises dos financiamentos públicos, governos e agências multilaterais intensificaram as práticas de prestação de contas (accountability) principalmente em questôes que envolviam financiamentos. Assim se incorporou a econometria, como um conjunto de idéias fundadas no valor econômico e de instrumentos capazes de medir a viabilidade econômica de um projeto, bem como os impactos econômicos de um programa executado.

Avaliação também tem sentidos de sanção e legitimação e seus contrários. Legitima e denega práticas, conteúdos, valores e sentidos. A noção de seleção e de organização social com o correr do tempo tornou-se muito forte, a ponto de ainda hoje estar arraigada indelevelmente em muitas práticas avaliativas, tanto nas escolas como nos âmbitos públicos dos concursos e dos exames.

A necessidade de organização seletiva da sociedade aumentou consideravelmente a partir do momento em que a sociedade veio se tornando mais complexa. A Revolução Francesa ampliou o acesso à educação básica e criou o sistema de classes, isto é, organizou os alunos conforme as capacidades individuais e idades. A escola deveria preparar servidores para os novos cargos e as funções do sistema de serviço público que os valores republicanos então organizavam. A Revolução Industrial promoveu a organização das atividades e dos postos de trabalho e estabeleceu os conceitos salariais relativos, gerando com isso também a afirmação de significados sociais e hierarquias de poder ligados aos lugares ocupados nas estruturas dos serviços e da produção. A avaliação teve, então, notável apelo e demanda, tanto para distribuir socialmente os indivíduos quanto para selecionar para o serviço público e os postos de trabalho, sempre baseada na noção de mérito individual. Desde então ela tem sido um importante instrumento para o estabelecimento e a mobilidade das classes de alunos, que se consolidou como a mais evidente forma de organização da escola moderna. 
Avaliação ética e política em função da educação como direito público ou...

Para mais eficaz e objetivamente dar conta das funções sociais que lhe foram outorgadas, a avaliação teve que se desenvolver tecnicamente, criando os testes escritos e o sistema de notação. Aí está uma primeira característica que colou na avaliação a ponto de parecer pertencer à sua essência: os testes escritos com fins de medida. Como se sabe, as universidades medievais praticavam apenas exercícios orais; posteriormente, os jesuítas utilizaram fartamente as competiçōes orais como proposta pedagógica. Os testes escritos são uma criação da escola moderna. Sua forma escrita liga-se à idéia de credibilidade pública, transparência e rigor. Ganharam tanta importância que acabaram interferindo fortemente na definição dos currículos e das propostas pedagógicas.

De um lado, os instrumentos de testes, provas, exames trouxeram mais precisão e força operacional ao sistema de medidas e de seleção. Por outro, determinaram uma concepção e uma prática pedagógicas que consistem basicamente na formulação dos deveres ou exercícios escolares e no controle por meio dos testes. Assim, a avaliação interfere incisivamente na organização dos conteúdos e das metodologias e vai legitimando saberes, profissóes e indivíduos, o que significa também produzir hierarquias de poder e privilégios. Como símbolo da legitimação de valores e privilégios sociais, os títulos e diplomas são instituídos formalmente, resultantes também eles da avaliação, e ganham grande importância na determinação das hierarquias e na distribuição dos indivíduos nos lugares que "de direito" e por mérito individual lhes corresponderiam na sociedade. A proliferação dos exames e concursos em grande parte deve-se às necessidades que as sociedades apresentam de distribuir os indivíduos nas diferentes posiçôes dos espaços sociais, segundo critérios de méritos pessoais, e de legitimar essa organização e a ideologia correspondente, bem como os conhecimentos, os privilégios e o direito às práticas profissionais, mediante a outorga de diplomas e títulos.

Tal é a importância dos exames no campo da avaliação que eles acabaram constituindo uma área de estudos - a docimologia. Esses estudos reafirmam uma concepção racionalista e empirista da avaliação, durante muito tempo quase totalmente identificada com exames, notação e controle.

Até há pouco tempo, falar de avaliação era "naturalmente" (aqui está a força do topos) falar da avaliação somativa, da nota, dos testes, dos controles, da verificação, do balanço. Assim, os estudos docimológicos desejam pertencer ao paradigma da Razão. (Vial, 2001, p. 41) 
Utilizando-se quase exclusivamente da medida e da seleção como instrumento técnico para efeito político de organização hierárquica do serviço público e do trabalho em geral, a avaliação de modo algum pode ser considerada neutra e ingênua. Ela transforma, isto é, produz efeitos, tanto para a vida individual como para a sociedade e para o Estado. Legitima valores e ideologias, justifica admissões e demissões, ascensões e reprovações, premiações e sanções, reforços e coerções na esfera comportamental, liberações e cortes de financiamentos etc. Justificada por um discurso conveniente, a avaliação como tecnologia de poder faz suas escolhas. $\mathrm{Na}$ escola, determina quem "passa de ano" e quem é retido, quais são os melhores e os piores, os inteligentes e os incapazes, os esforçados e os preguiçosos, os educados e os indisciplinados. $\mathrm{Na}$ vida social, quem merece ter as melhores posições e mais poderes, em razão de seus méritos, e quem será excluído, por mediocridade e/ou desinteresse.

Nos processos ditos de garantia da qualidade costumam associarse três conceitos: qualidade, avaliação e inovação. Muito freqüente é a associação dos dois primeiros. A avaliação é comumente entendida como um sistema de coerências entre o ser (a realidade encontrada ou realizada) e o dever ser (o padrão ideal, preconcebido); e também como um sistema de distinções entre o certo e o errado, os pontos fortes e os fracos, os acertos e desvios. Pertinência (relação entre projeto institucional e necessidades científicas e sociais), eficácia (coerência entre as práticas e os objetivos) e eficiência (coerência entre insumos e resultados) são três critérios considerados quando usualmente se quer constatar e verificar níveis de qualidade, segundo padróes de coerência e medida de desvios ou distâncias entre o que é e o que deveria ser.

Esta concepção põe a ênfase sobre os aspectos mais identificados com as produçôes e as expectativas econômicas, quase sempre relativamente àquilo que é quantificável. Em outras palavras: põe em relação um referido (o constatado, o objeto em pauta, o realizado, o verificável em dado momento) com um referente (a norma, o ideal, o esperado). Importante observar que aí não há necessariamente questionamento a respeito das normas, dos critérios e dos objetivos. Seu núcleo central é a verificação, o controle dos resultados, a constatação da coerência e das diferenças encontradas entre o realizado e o idealizado, os resultados e a norma preestabelecida. Esse procedimento é conservador, fechado, na medida em que reproduz os esquemas mentais estabelecidos com anterioridade e exterioridade. Não permite a interação dos sujeitos idiossincrá- 
Avaliação ética e política em função da educação como direito público ou...

ticos com o objeto, com o pretexto de que este deve ser isento das contaminações da subjetividade e não dependente do contexto.

$\mathrm{O}$ critério da medida da coerência, embora se justifique em muitos casos, não é totalmente suficiente para tratar fenômenos com enorme grau de complexidade, dinamismo e conteúdos simbólicos como é o caso da educação. As dinâmicas educativas não se referem somente aos planos organizacionais e aos significados intrínsecos e internos das práticas. Elas também se projetam em problemáticas públicas e lançam questôes que escapam à rigidez da racionalidade administrativa.

A avaliação da educação tem atribuído ênfase ao uso de técnicas objetivas que focalizam resultados e aquisiçôes. Por serem mais facilmente organizáveis do ponto de vista operacional e dada a imagem de objetividade e isenção que transmitem, as técnicas de medição e explicação têm sido bastante utilizadas. De modo especial, essa tradição esteve fortemente presente até os anos de 1960, nos Estados Unidos e na Inglaterra, e agora é largamente utilizada em vários países. Na pesquisa, aplicaram-se centralmente as práticas da cienciometria, que usualmente quantificam a produção científica e alguns aspectos que indicariam reconhecimento de qualidade, como números de citações em revistas indexadas etc. No ensino, o foco da avaliação muitas vezes consistiu, e ainda consiste, em mensurar os desempenhos dos alunos em exames. Versóes brasileiras dessas práticas se realizam respectivamente na quantificação da produção científica e técnica, parte importante da avaliação da pós-graduação, e no "Provão", instrumento que se propunha a determinar a qualidade de um curso de graduação, segundo os desempenhos dos seus estudantes em um exame nacional, e acabou tendo um enorme impacto na explosiva privatização da educação superior brasileira, a partir da segunda metade da década de 1990.

As avaliações de caráter objetivista são francamente utilizadas para a orientação do mercado, onde as noções de qualidade se assemelham a produtividade e eficiência, e para uma atualização da teoria do capital humano, que restringe a formação à capacitação profissional. $\mathrm{O}$ texto abaixo, de Erik Jan Lane, refere-se à universidade sueca, porém pode também servir para mostrar as grandes marcas das reformas universitárias pelo mundo afora.

A qualidade substituiu a igualdade como conceito dominante da vida acadêmica. A eficiência volta a ser importante e se considera que a pesquisa 
avançada e a formação são de vital importância para o desenvolvimento futuro da sociedade. (...) Finalmente está a questão da produtividade. Cada vez se compartilha mais amplamente a idéia de que os recursos destinados à educação superior devem ser uma inversão que produza seus benefícios, tanto no sentido de que seja socialmente produtiva, como no sentido de que a formação acadêmica é produtiva quando os êxitos estão relacionados com os montantes investidos. (Lane, apud Neave \& Van Vught, 1994, p. 269)

As restrições orçamentárias e a exigência de que a educação superior se torne mais útil ao fortalecimento do mercado e à saúde econômica das empresas transformou a accountability (prestação de contas, responsabilização, responsividade) em critério central da avaliação, desde as duas últimas décadas do século passado. A responsabilidade de demonstrar eficiência e produtividade é tanto maior quanto mais reduzidos vão se tornando os orçamentos das instituições. Ao mesmo tempo, os Estados vão desenvolvendo com mais intensidade a vocação legisferante para assegurar a correção contábil e a eficácia gerencial. Os organismos multilaterais e os países desenvolvidos, que fazem parte da OCDE, praticam-na de forma contábil e gerencialista, pois, para fins de controle, interessa aos governos e agências de financiamento ter informaçôes acerca do desempenho econômico-financeiro, dos rendimentos escolares, da eficácia administrativa. Os instrumentos e as práticas dessa responsabilização e dessa responsividade contábil e gerencialista se constituem muito mais como controle que como avaliação, têm muito mais um sentido burocrático e fiscalizador que propriamente educativo ou formativo. Promovem a ideologia da eficácia da gestão segundo os modelos empresariais, centrados nos ajustes estruturais de forte concentração de poder, porém não vinculam a eficácia administrativa às funções pedagógicas e científicas e às finalidades essenciais da educação.

Levada a limites extremos, essa responsabilização e essa responsividade produzem um importante deslocamento de sentido, que consiste na redução do exercício participativo na vida social, na cidadania pública, enfim, na responsabilidade pedagógica, política e científica da educação ante a sociedade, à exigência de prestar contas aos governos e às agências de financiamento e regulação. No limite, acabam restringindo as finalidades públicas da avaliação, concebida então como controle e verificação da eficiência e rentabilidade das instituições, dos cursos, dos estudantes, em conformidade com parâmetros externos e superiores. 
Avaliação ética e política em função da educação como direito público ou...

Os mecanismos de controle dos resultados tendem a fazer uma abstração dos contextos e dos fatores humanos que os envolvem e engendram. Os produtos são apresentados como quantidades desligadas dos fenômenos causais e dos significados idiossincráticos. Esse procedimento é muito útil para a elaboração de classificaçōes, informações objetivas, mas não se preocupa em pôr em foco de conceituação as ações educativas e os seus resultados. Assim, é bastante conveniente para os tecnocratas, mas pouco vale para melhorar os processos pedagógicos, a formação, o ensino, as aprendizagens, a produção dos conhecimentos necessários para o desenvolvimento da sociedade.

Granheim \& Lundgren consideram haver três sentidos principais nessas avaliações tecnocráticas: uma direção legal e burocrática, que impõe um quadro normativo e punitivo, uma direção econômica, que estabelece os sistemas de valor por meio da distribuição de recursos, e uma direção ideológica, que compreende as diretrizes educativas. Para esses autores, ocorre aí um grande risco de que se "dê à avaliação um sentido tecnocrático e que se passe a exigir burocraticamente o cumprimento de obrigações" (Granheim \& Lundgren, 1992, p. 18 e 19).

Quando a avaliação é apropriada pelas instâncias de poder, sem uma interlocução com os educadores, enfraquece sua potencialidade formativa em favor das funções burocráticas, controladoras e economicistas.

Os processos de avaliação nessa perspectiva se transformam em mecanismos de controle dos resultados. Esse mecanismo de deslocamento dos processos para os produtos valoriza a eficiência, a produtividade. Mediante procedimentos de quantificação e comparação, introduzem no sistema um forte componente de competitividade nos níveis internos das instituições educativas e nas suas relaçôes com as demais. Esses processos avaliativos são instrumentos de competição, e não de solidariedade e cooperação, que são valores históricos da universidade. Ao comparar a quantidade de produtos das instituições, essa avaliação objetivista e tecnocrática afirma a produtividade como valor de referência e determina, centralizadamente, os objetivos e as atividades da comunidade universitária.

A avaliação objetivista e produtivista vincula-se às ideologias do individualismo e da competitividade, próprios de uma sociedade cujo valor central é o mercantilismo. À epistemologia objetivista correspondem 
os interesses individualistas e utilitaristas. De acordo com essa racionalidade, quanto mais produtos úteis, isto é, valiosos para a economia, alcançar uma sociedade, mais feliz ela é. Felicidade social e utilidade geral, assim, equivalem-se, são coincidentes. A felicidade geral é medida por instrumentos e muitas vezes confunde-se com os indicadores. Por exemplo, ela se identifica com o produto nacional bruto, as taxas de inflação, os índices de desenvolvimento humano, as pontuações e classificações de méritos etc.

Importante insistir: a avaliação é o principal instrumento para assegurar o êxito e a direção das reformas. Ainda que de modos diferentes, a avaliação esteve a serviço da privatização na Inglaterra, desde 1980, e em muitos outros países, especialmente na América Latina, a partir dos anos de 1990. No Brasil, essa relação entre avaliação (controle) e mercado (privatização) se tornou forte a partir de 1995. O Relatório Jarrat (1985) usou a expressão-chave que serve tanto para o caso da Inglaterra quanto para outros países: as instituições de educação superior devem ser parecidas com as "empresas de negócios".

Em questōes de aprendizagem, persistiu durante a maior parte do século XX a crença de que um bom instrumento de medida, especialmente o de cunho psicométrico, garantiria resultados confiáveis e justos, pois supostamente isentos de contaminaçôes. $\mathrm{O}$ paradigma positivista asseguraria a objetividade necessária à ciência e à técnica neutras e despojadas de valores, evitando argumentos e evidências de que normas e regras são produtos de processos históricos movidos por contradições, escolhas, interesses e valores que interagem em condiçóes sociais concretas.

As visões de mundo acentuadamente objetivistas organizam esquemas fechados de compreensão da realidade e se traduzem por uma ética tendencialmente utilitarista, pragmatista e individualista, fazendo crer que o progresso resulta mecanicamente da gestão eficiente, do uso racional dos recursos e da natureza desenvolvimentista da ciência e da técnica.

O paradigma mecanicista, sustentando a idéia da verdade sobre a noção de neutralidade que os números, os planejamentos rigorosos e os instrumentos objetivos supostamente apresentam, produz uma positivação do mundo, mediante as técnicas de quantificação, de medições controladas, de comprovações dos resultados, da estabilização e particularização da realidade, para fins de inferências e produção de dados objetivos e repetíveis (Cook \& Reichardt, 1995, p. 29). 
Avaliação ética e política em função da educação como direito público ou...

Esse enfoque avaliativo tem sido largamente utilizado pelos governos e por agências multilaterais. Evidentemente, a quantificação, a objetividade, a comparabilidade são aspectos importantes de um processo avaliativo. Erro seria não os utilizar, o que levaria aos vícios de um subjetivismo exclusivista. Porém, também é um grande equívoco utilizá-los exclusivamente, como únicos, incorrendo-se então numa extrema quantofrenia ou no erro de equiparar a ciência à verdade. Diz House:

Em sua forma extrema, o objetivismo epistemológico exclui por completo o não-quantitativo: o que existe pode ser medido. A redução a números equipara-se às vezes à objetividade. Em boa medida, as origens deste empirismo e deste objetivismo extremos podem ser encontradas na primitiva epistemologia da filosofia liberal. (House, 1994, p. 50)

A objetividade, como idéia regulativa, de modo algum deve ser negada. Rigor científico, verificabilidade, integridade, capacidade de construir representaçôes consistentes são características da objetividade que devem ser afirmadas. Critico o objetivismo, exagero que faz coincidir objetividade e verdade, que defende a idéia da neutralidade da ciência e recusa a dimensão social e histórica do conhecimento. A objetividade, para ser legítima e mais amplamente reconhecida, precisa reconhecer a dimensão social e intersubjetiva do conhecimento. Não é possível objetividade sem subjetividade, não há o quantitativo sem o qualitativo, só mediante teorias da complexidade se pode compreender globalmente um fenômeno humano, que por natureza é polissêmico - e este é o caso da educação, como também o é da avaliação.

\section{Epistemologia subjetivista em avaliação}

A partir da década de 1970, nos Estados Unidos, as práticas objetivistas tiveram que dividir espaços com uma epistemologia mais aberta, transdisciplinar, que requer operações de produção de juízos de valor e aborda os fenômenos do campo social por meio de metodologias complexas. Desde então, a epistemologia subjetivista passou a competir e conviver (não sem dificuldades) com a epistemologia objetivista. A sociedade norte-americana experimentava grande aceleração em termos de complexidade, de modo que os problemas sociais já não podiam ser 
compreendidos e, muito menos, solucionados, mediante visões e estratégias simples. A avaliação educativa já não podia contentar-se com meras verificações, constatações e medidas. A esse propósito diz Helen Simons, em texto escrito em 1988:

Ao focar a atenção exclusivamente na aquisição por parte do aluno de objetivos de aprendizagem predefinidos, o governo conserva uma visão da avaliação que já se encontrava ultrapassada nos anos 60 quando se reconhecia a necessidade de análises mais sofisticadas, que permitissem uma utilização da "avaliação" como instrumento de "inovação curricular". (Simons, 1993, p. 158)

A epistemologia subjetivista, também conhecida por holística, fenomenológica, naturalista, conforme o aspecto sobre o qual recaem as ênfases, não se sustenta sozinha. Não sem se combinar com a linguagem e os instrumentos próprios da racionalidade objetivista, ela faz emergir práticas em que se valorizam as atitudes reflexivas e cooperativas dos atores envolvidos nas açôes educativas. Para além das simples medidas, valoriza a construção de processos sociais de comunicação baseada na autonomia e não no poder, de tal modo que "o conhecimento adquirido no decorrer da avaliação seja utilizado de forma pertinente e defendido pela maioria dos atores educativos" (Simons, 1993, p. 165).

A epistemologia subjetivista tem uma perspectiva de compreensão da realidade diferente daquela da epistemologia objetivista. Para a epistemologia subjetivista, a realidade é complexa, dinâmica, aberta e polissêmica, a verdade é, portanto, relativa e dependente das experiências humanas concretas, a ciência e a técnica estão mergulhadas na ideologia, os valores estão impregnados das contradições sociais, e tudo isso impóe a necessidade de fazer uso também das abordagens qualitativas e intuitivas. Cook \& Reichardt afirmam que esse paradigma tende a apresentar os seguintes atributos: defende os métodos qualitativos; faz observação naturalista, sem controle; tende ao subjetivismo; desenvolve a perspectiva interna; orienta-se aos descobrimentos, por vias exploratórias, descritivas e indutivas; orienta-se ao processo; considera que a validade consiste nos dados reais e ricos de significação; não é generalizável; faz estudos de casos isolados; é holística; assume uma realidade dinâmica (Cook \& Reichardt, 1995, p. 29).

Essa perspectiva defende a idéia de que, se a avaliação tem por objeto uma realidade dinâmica e complexa, precisa ela também ser consi- 
Avaliação ética e política em função da educação como direito público ou...

derada polissêmica, plurirreferencial. Então, só pode ser compreendida mais adequadamente por meio de múltiplos enfoques e ângulos de estudos, ou seja, por uma epistemologia da complexidade.

O reconhecimento da avaliação como fenômeno plurifacetado e de responsabilidade social significa também admitir a sua dimensão ética, para além de sua complexidade epistemológica. Atribuir valor absoluto de verdade e objetividade aos números e seus efeitos de seleção e classificação é querer esconder e abafar o fato de que o campo social é penetrado de valores, interesses e conflitos. É esse caráter ético e, portanto, político que coloca a avaliação no centro das reformas e dos conflitos, pois o que está em jogo e em disputa é o modelo de sociedade. "Essas tensões, conflitos e ambigüidades" (da avaliação são consideradas) "práticas sociais relacionadas com fins sociais" (Popkewitz, 1992, p. 96).

Se nenhuma avaliação é isenta de valores e sempre produz efeitos que de alguma forma a todos afetam, dos concernidos requer capacidades não só técnicas, mas também sociais e éticas. Como o caráter político da avaliação educativa é densamente habitado pelo sentido ético do bem comum, ela deve estar orientada para o aprofundamento da autonomia pública. Como empreendimento social, a avaliação deve organizar os conjuntos de indivíduos, idéias, ações, estruturas e relações com os objetivos de compreender e melhorar as instituições educativas.

A melhora da qualidade educativa é uma construção coletiva. É a participação ativa de sujeitos em processos sociais de comunicação que gera os princípios democráticos fundamentais para a construção das bases de entendimento comum e de interesse público. Esse processo social também é potencialmente rico de sentido formativo, inclusive para os sujeitos que a ele se dedicam. Como é corrente em todo processo complexo de comunicação, em que se encontram interlocutores de distintos grupos, a avaliação participativa e democrática é penetrada de muitas contradições e disputas, que certamente trazem dificuldades e incertezas, mas sobretudo propiciam muitas possibilidades de aprendizagem e de experiências ricas dos significados da vida social.

A educação superior deve ser avaliada não simplesmente a partir de critérios do mundo econômico e não somente com instrumentos que matematizem a qualidade sob as justificativas de desempenho, eficiência e produtividade, mas, sobretudo, deve colocar em julgamento os significados de suas ações e construções com relação às finalidades 
da sociedade. Certamente isso exige a superação de noções estreitas de qualidade, transferidas do mercado, por uma concepção complexa, que, além de aspectos mais visíveis e mensuráveis, para além da operatividade e da funcionalidade produtiva, incorpore ainda os sentidos e valores da construção da sociedade democrática. Dessa forma, a avaliação estaria ajudando a educação superior a formar cidadãos equipados de competências éticas, científicas e políticas requeridas pela sociedade.

\section{Conclusão}

Este texto discutiu dois modelos, ou dois enfoques, ou duas perspectivas, ou duas lógicas, ou duas perspectivas, ou dois paradigmas ou ainda duas epistemologias de avaliação. ${ }^{1}$ Simplificando, um desses enfoques faz a avaliação desenvolver-se como controle e tem como objetivo a verificação e a medida da conformidade. O controle verifica e constata o realizado, em atitude conservadora e voltada ao passado. No outro paradigma, a avaliação é ação de atribuição de valor e produção de sentidos. Sua base é o real, porém não simplesmente como produção passada e sentido já acabado, mas, sobretudo, como projeto aberto ao futuro. Trata-se de pôr em foco de conceituação, isto é, de questionar os significados das ações e das idéias, tendo como referência os valores fundacionais da educação e, como perspectiva, a construçãao do futuro.

Como diz Vial, a avaliação vive um "conflito entre dois logos, dois registros de palavras, duas falas: o da Ratio ('avaliar é ser justo, objetivo') e o do Pathos ('avaliar é acompanhar, cumprir, amar')" (Vial, 2001, p. 41). Esses dois sistemas de idéias e práticas, ou seja, paradigmas, são distintos e contraditórios, porém não se excluem mutuamente. Não se trata de simples oposição, em que uma parte deve ser aceita e a outra deve ser rejeitada. Não se trata de adotar exclusivamente o controle (medida, verificação, constatação, o sentido já dado, classificação, seleção etc.) ou, tampouco, também exclusivamente, de adotar procedimentos subjetivistas sem base em dados da realidade. As duas epistemologias representam duas visões de mundo distintas, até mesmo concorrentes, porém são complementares e não excludentes.

O controle, quando isolado, é insuficiente, conservador, pode ser autoritário e não favorece a autonomia. É uma intervenção fechada, terminada em si mesma, centrada sobre um objeto desligado de seu con- 
Avaliação ética e política em função da educação como direito público ou...

texto, ou sobre produtos sem processos. Ao buscar as correspondências e singularidades e ao estabelecer a relação de conformidade/inconformidade entre o ser e o dever ser, o controle apresenta a norma como naturalmente válida e inquestionável. Em geral, os critérios, procedimentos e instrumentos do controle são determinados externamente, sem a participação efetiva dos educadores, muitas vezes obedecendo à lógica dos organismos e das agências de regulação e financiamento. É certo que o controle produz importantes efeitos. Entretanto, tende a produzir mais do mesmo. Assim, é importante quando se objetiva consolidar práticas e fazer ajustes, porém não quando se quer pôr em questão os significados e os valores, tampouco quando se pretende fazer da avaliação um consistente processo ético e técnico de formação humana.

A avaliação, como produção de sentidos, reflexão sobre valores e significados, tem um grande potencial educativo. Sem deixar de ser objetiva e utilizar instrumentos técnicos, e não se satisfazendo com a mera verificação e checagem de produtos e sua conformidade com uma norma, a avaliação como produção de sentidos alimenta debates, interrogase sobre os significados, as causalidades e os processos, trabalha com a pluralidade e a diversidade, abre possibilidades de emancipação, construção, dinamização. Se a finalidade essencial da educação é a formação, em seu sentido pleno e não restrito à capacitação técnica, então a avaliação deve se realizar como um processo e um projeto, continuamente em construção, que, fundamentalmente, coloca em foco de conceituação e questionamento os significados da formação que se vão produzindo no conjunto das práticas institucionais, pedagógicas, científicas e sociais. Então, a avaliação educativa deverá tratar, em última instância, dos valores da existência humana, portanto da sociedade humana, que uma instituição prioriza em suas atividades formativas.

Controle e produção de sentidos complementam-se, não se excluem. Educação é formação plena e dinâmica, é construção e promoção da autonomia pessoal e pública dos cidadãos e da sociedade. A ser assim, carrega um forte significado ético-político. O sentido ético da avaliação dá conteúdo à afirmação das subjetividades, papel fundamental da educação, que passa pela produção de sentidos dos sujeitos. Então, avaliação e educação, bem como avaliação e autonomia, devem manter entre si uma relação de sinergia.

Recebido e aprovado em setembro de 2004. 


\section{Nota}

1. Não é aqui lugar e hora para discutir as nuanças semânticas que distinguiriam estes termos.

Referências bibliográficas

COOK, T.D.; REICHARDT, C.S. Métodos cualitativos y cuantitativos en investigación evaluativa. 2. ed. Madrid: Morata, 1995.

GRANHEIM, M.K.; LUNDGREN, U.P. La dirección por objetivos y la evaluación en la educación noruega. Revista de Educación, Madrid, n. 299, p. 7-42, 1992.

HOUSE, E. Evaluación, ética y poder. Madrid: Morata, 1994.

LANE, J.E. Suecia y las consecuencias de la reforma educacional. In: Neave, G.; Van Vught, F.A. Prometeo encadenado: Estado y educación superior en Europa. Barcelona: Gedisa, 1994.

MCCORMICK, R.; JAMES, M. Evaluación del curriculum en los centros escolares. Madrid: Morata, 1997.

NEAVE, G.; VAN VUGHT, F.A. Prometeo encadenado: Estado y educación superior en Europa. Barcelona: Gedisa, 1994.

POPKEWITZ, T. Algunos problemas y problemáticas en la producción de la evaluación. Revista de Educación, Madrid, n. 299, p. 95-118, 1992.

SIMONS, H. Avaliação e reforma das escolas. In: Estrela, A.; NóvOA, A. (Org.). Avaliações em educação: novas perspectivas. Porto: Porto, 1993.

SIMONS, H. Evaluación democrática de instituciones escolares. Madrid: Morata, 1999.

VIAL, M. Prefácio: ensaio sobre o processo de referenciação; o avaliador em trajes de luz. In: Bonniol, J.-J.; VIAL, M. Modelos de avaliação: textos fundamentais. Porto Alegre: Artmed, 2001.

VIAL, M. Se former pour évaluer : se donner une problématique et élaborer des concepts. Bruxelles: De Boeck, 2001.

VOGLER, J. L'évaluation. Paris: Hachette Livre, 1996. 